\title{
Using Bacterial Artificial Chromosomes in Leukemia Research: The Experience at the University Cytogenetics Laboratory in Brest, France
}

\author{
Etienne De Braekeleer, ${ }^{1,2,3}$ Nathalie Douet-Guilbert, ${ }^{1,2,3}$ Audrey Basinko, ${ }^{1,2,3}$ \\ Frédéric Morel, ${ }^{1,2,3}$ Marie-Josée Le Bris, ${ }^{3}$ Claude Férec, ${ }^{1,2,4}$ and Marc De Braekeleer ${ }^{1,2,3}$ \\ ${ }^{1}$ Faculté de Médecine et des Sciences de la Santé, Université de Brest, 22, avenue Camille Desmoulins, CS 93837, \\ F-29238 Brest Cedex 3, France \\ ${ }^{2}$ Institut National de la Santé et de la Recherche Médicale (INSERM), U613, Brest 29238, France \\ ${ }^{3}$ Service de Cytogénétique, Cytologie et Biologie de la Reproduction, CHRU Brest, Hôpital Morvan, Brest 29609, France \\ ${ }^{4}$ Laboratoire de Génétique Moléculaire et d'Histocompatibilité, CHRU Brest, Hôpital Morvan, Brest 29609, France \\ Correspondence should be addressed to Marc De Braekeleer, marc.debraekeleer@univ-brest.fr
}

Received 15 June 2010; Accepted 7 December 2010

Academic Editor: Hans Konrad Muller

Copyright (C) 2011 Etienne De Braekeleer et al. This is an open access article distributed under the Creative Commons Attribution License, which permits unrestricted use, distribution, and reproduction in any medium, provided the original work is properly cited.

\begin{abstract}
The development of the bacterial artificial chromosome (BAC) system was driven in part by the human genome project in order to construct genomic DNA libraries and physical maps for genomic sequencing. The availability of BAC clones has become a valuable tool for identifying cancer genes. We report here our experience in identifying genes located at breakpoints of chromosomal rearrangements and in defining the size and boundaries of deletions in hematological diseases. The methodology used in our laboratory consists of a three-step approach using conventional cytogenetics followed by FISH with commercial probes, then BAC clones. One limitation to the BAC system is that it can only accommodate inserts of up to $300 \mathrm{~kb}$. As a consequence, analyzing the extent of deletions requires a large amount of material. Array comparative genomic hybridization (array-CGH) using a BAC/PAC system can be an alternative. However, this technique has limitations also, and it cannot be used to identify candidate genes at breakpoints of chromosomal rearrangements such as translocations, insertions, and inversions.
\end{abstract}

\section{Introduction}

Since chromosome banding techniques have been applied to the analysis of chromosomal aberrations in leukemia and cancer, several hundreds of recurring chromosomal breakpoints have been identified. They also allowed the recognition of regions of nonrandom copy number changes such as deletions. These chromosomal abnormalities point to the location of genes involved in the genesis and progression of leukemia and cancer (http://www.ncbi .nlm.nih.gov/sites/entrez? $\mathrm{db}=$ cancerchromosomes).

The development of molecular cytogenetic methodology (fluorescent in situ hybridization-FISH) improved the level of resolution and increased the number of recurring chromosomal abnormalities, notably by recognizing cryptic translocations and deletions. However, the level of resolution in cancer cytogenetics is not fine enough to be used for positional cloning of genes at chromosomal breakpoints or those tumor suppressor genes mapping to regions subjected to deletion.

Therefore, the availability of large-insert genomic librairies such as bacterial artificial chromosomes (BACs) is a valuable tool for identifying cancer genes. Indeed, it is now widely used in sequencing efforts and in studies of genomics and functional genomics [1-3].

We illustrate here by several examples our experience at the University Cytogenetics Laboratory in Brest (France) using BAC clones to identify genes at chromosomal breakpoints and define commonly deleted regions in myelodysplastic syndromes, myeloproliferative neoplasms and leukemia. 


\section{Methodology}

A three-step methodology consisting in conventional cytogenetics followed by FISH with commercial probes, then BAC clones is currently used in the laboratory.

2.1. Conventional Cytogenetics. Cytogenetic analysis is performed on bone marrow cells of patients at the time of the diagnosis and/or relapse(s). Bone marrow cultures are synchronized for 17 hours by fluorodeoxyuridin (FudR $\left.10^{-7} \mathrm{M}\right)$, before being released by thymidine $\left(10^{-5} \mathrm{M}\right)$ for 6 hours. They are then exposed to colcemid and standard harvested. The chromosomes are R-banded and the karyotypes described according to the International System for Cytogenetic Nomenclature (ISCN 2005) [4].

2.2. FISH Analyses with Commercially Available Probes. Should one or several chromosomal abnormalities be identified by conventional cytogenetics, FISH studies using commercially available probes are performed on the same fixed material, stored in fixative at $-20^{\circ} \mathrm{C}$ until utilization, as the conventional cytogenetic analyses. These probes include whole chromosome paints (WCP), chromosome enumeration probes (CEP), locus-specific identifiers (LSI) and subtelomeric specific probes. In case of noninformativeness of the R-banded karyotypes, 24-color FISH using MetaSystems'24Xcyte probe kit (MetaSystems, Altlussheim, Germany) is applied to characterize the chromosomal abnormalities. All probes are used according to the suggested manufacturers' protocols.

Furthermore, cryptic rearrangements (translocations, deletions, insertions) of ubiquitous genes such as the $M L L$ and RUNX1 (AML1) genes are searched for in specific hematological disorders.

2.3. FISH Analyses with BAC Clones. We identify the BAC clones of interest through the human genome browser database of the genome bioinformatics group at the university of California at Santa Cruz (http://genome.ucsc.edu/) and ensembl genome data resources of the Sanger Institute genome database (http://www.ensembl.org/). They are then ordered by Internet on the site of the Children's Hospital Oakland Research Institute in Oakland, California (http://bacpac.chori.org/).

When received, bacterial cultures are prepared from a single colony picked from a selective plate in the presence of chloramphenicol. Plasmids are obtained from bacterial cultures grown in the presence of chloramphenicol $(10 \mathrm{mg} / \mathrm{L})$. After having lysed bacteria using SDS1\%/NaOH $0.2 \mathrm{~N}$, DNA is purified from RNA, proteins and other cellular contaminants. Probes are then labelled by nick translation in Spectrum Orange (Nick Translation Kit, Abbott, Rungis, France) or in FITC (Prime-it Fluor Fluorescence Labeling Kit, Stratagene, Amsterdam, Netherlands). All BAC clones are applied to normal lymphocyte metaphases to confirm their chromosomal location [5].
Because of the limited resolution and the usual poor morphology of the chromosome preparation in haematological malignancies, we use, in first intention, an appropriate set of BAC clones located every 1.5 to $2 \mathrm{Mb}$ around the breakpoint(s). Contig BACs are then used to precisely determine the breakpoint(s). Several FISH assays can be carried out consecutively on the same metaphases after de-hybridization, following the protocol described by Wang et al. [6].

After hybridization, the slides are counterstained with 4-6-diamino-2-phenyl-indole-dihydrochloride (DAPI). The preparations are examined using a Zeiss Axio Plan Microscope (Zeiss, Le Pecq, France). Images acquisition is performed using a CCD camera and analyzed using the ISIS program (In Situ Imaging System) (MetaSystems, Altlussheim, Germany).

\section{Identification of Genes at Chromosomal Breakpoints}

We use BAC clones to precisely locate the breakpoints of recurrent chromosomal abnormalities. This is illustrated by the following three examples.

\subsection{Identification of Genes Involved in Newly Recognized} Recurrent Translocations. Two patients, a 13-year-old boy and a 40-year-old woman, were first seen because of a history of asthenia. At admission, both presented signs of disseminated intravascular coagulation. A diagnosis of acute myeloid leukemia, M1 subtype in the FAB classification, without maturation in the $\mathrm{WHO}$ classification was made in both patients [7].

A chromosomal translocation, $\mathrm{t}(10 ; 17)(\mathrm{p} 15 ; \mathrm{q} 21)$, was found in both patients. Initial FISH studies using the LSI PML/RARA dual-color translocation probe (Abbott, Rungis, France) showed the RARA signal to remain on the derivative chromosome 17, providing evidence that the translocation breakpoint was telomeric to the RARA locus.

Twelve and $14 \mathrm{BAC}$ clones were selected on chromosomes 10 and 17, respectively (Figure 1 ). The breakpoint occurred in RP11-10D13 on chromosome 10 and in RP11-379D19 on chromosome 17 in both patients. Five and 6 BAC clones spanning both breakpoint sites on chromosomes 10 and 17 were hybridized to confirm their location. Clone RP11$10 \mathrm{D} 13$ is located in band 10p15.3 and spans the ZMYND11 and DIP2C genes. The ZMYND11 gene codes a corepressor of transcription through recruitment of $\mathrm{N}-\mathrm{CoR}$ and the DIP2C gene a member of the disco-interacting protein homolog 2 family that shares strong similarity with a Drosophila protein which interacts with the transcription factor disco. Clone RP11-379D19 is located in band 17q21.33 and contains the NME1 gene, which might regulate different stages of the differentiation process during hematopoiesis, depending on the specific cellular lineage. Work is still underway to determine the partner gene on chromosome 10 and whether this putative fusion gene is transcribed.

3.2. Identification of New Gene Partners Fusing with Already Known Genes: The ABL1 Example. This 11-year old boy 


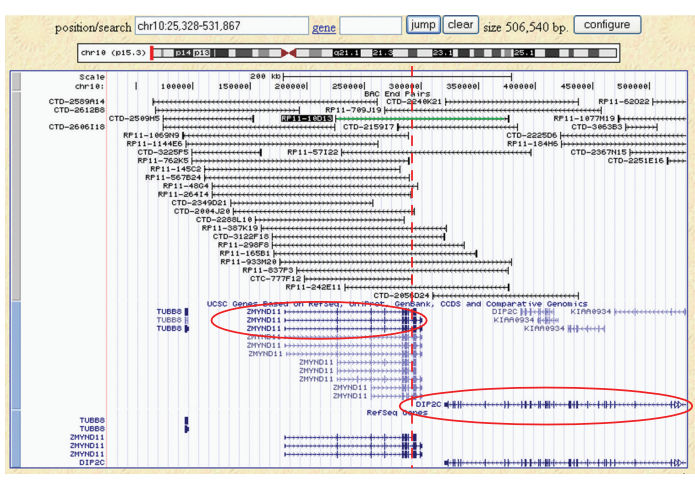

(a)

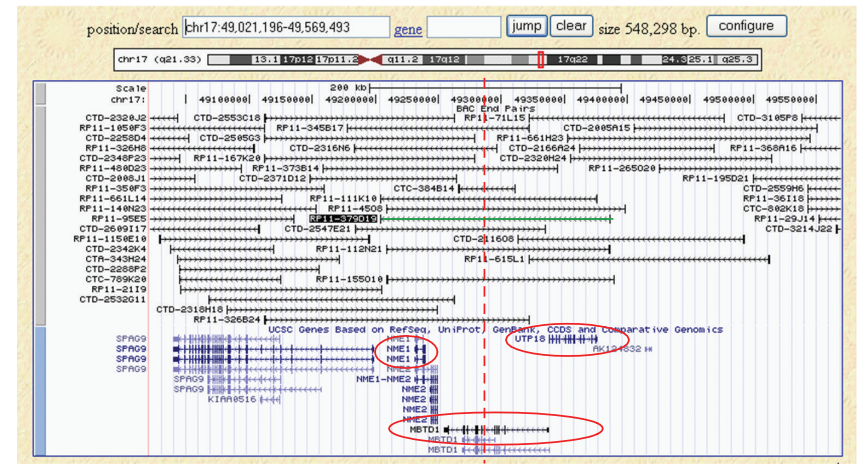

(b)

FIGURE 1: Identification of breakpoints involved in a newly recognized recurrent translocation, $t(10 ; 17)(p 15 ; q 21)$. (a) Representation of the breakpoint (dotted line) on the short arm of chromosome 10 for both patients by FISH with BACs. Applied BAC clones are bordered; candidate genes are surrounded. (b) Representation of the breakpoint (dotted lines) on the long arm of chromosome 17 for both patients by FISH with BACs. Applied BAC clones are bordered; candidate genes are surrounded.

was first seen for consolidation chemotherapy of a pre$B$ acute lymphoblastic leukemia that had been diagnosed elsewhere. Subsequently, he developed relapse, at which time karyotyping of bone marrow cells showed a $\mathrm{t}(1 ; 9)(\mathrm{q} 24 ; \mathrm{q} 34)$. Using LSI bcr/abl dual extra-signal (ES) color probe (Abbott, Rungis, France) in FISH experiments, three red signals were seen, one on the normal chromosome 9 , one on the $\operatorname{der}(9)$ and another on the $\operatorname{der}(1)$, signing the $t(1 ; 9)$ with involvement of the $A B L 1$ gene.

To map the breakpoints of the $\mathrm{t}(1 ; 9)$ (q24;q34), FISH was performed with appropriate sets of BAC clones. One BAC in band 9q34, RP11-83J21 containing the ABL1 gene and 16 on chromosome arm 1q were ordered. The probe from chromosome 9 was labelled by nick translation in Spectrum Orange and those from chromosome 1 in Spectrum Green. Split signals were observed for RP11-83J21 and RP11232M22. Cohybridization with these two probes show two yellow fusion signals (Figure 2) [8]. Clone RP11-232M22 is located in band 1q24.2 and contains the RCSD1 gene, which codes a protein kinase substrate, CapZIP (CapZ-interacting protein). This may influence cytoskeleton regulation and/or cell migration.

RT-PCR confirmed that the ABL1-RCSD1 fusion gene was transcribed. Sequencing revealed that the PCR product consisted of the first 3 exons of the $A B L 1$ gene fused to RCSD1 starting from exon 4.

\subsection{Identification of New Gene Partners Fusing with Already} Known Genes: The MLL Example. Most of the MLL gene breakpoints involved in fusion genes occur in a region called breakpoint cluster region (BCR). This led to the development of a long-distance inverse-polymerase chain reaction (LDIPCR) used to identify the MLL fusion partner genes involved in chromosomal rearrangements [9].

A 5 month-old-boy was first seen at the pediatric emergency room for left hemiplegia and right hemianopsia. A diagnosis of acute myelomonoblastic leukemia

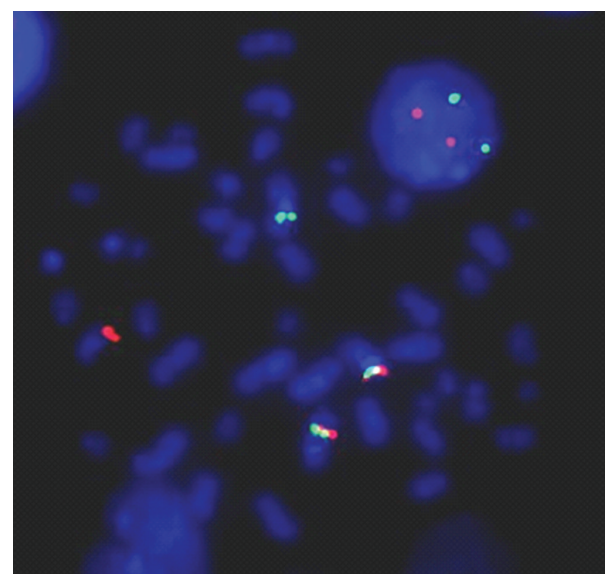

FIGURE 2: Identification of a new partner gene, RCSD1, fused to $A B L 1$ in acute lymphoblastic leukemia. Dual-color FISH using RP11-83J21 (labeled in spectrum orange) and RP11-232M22 (labeled in spectrum green) showing two fusion genes.

(FAB classification type 4) with severe diffuse intravascular coagulopathy was made [10]. Cytogenetic analysis performed on bone marrow cells at diagnosis showed a $46, \mathrm{XY}$,ins $(11 ; \mathrm{X})$ (q23;q28q12). FISH analysis using the LSI MLL dual color probe (Abbott, Rungis, France) confirmed the disruption of the $M L L$ gene and showed the insertion of chromosomal material between the green $\left(5^{\prime}\right.$ region of $\left.M L L\right)$ and red ( $3^{\prime}$ region of $\left.M L L\right)$ signals (Figure $3(\mathrm{a})$ ).

Sequence analysis of the PCR amplimers obtained by LDI-PCR (Figure 3(b)) revealed that the $5^{\prime}$ region of $M L L$ (break in intron 10) was fused in-frame with the $3^{\prime}$ region of Filamin a (FLNA) (break in intron 19), a gene located in chromosomal band Xq24 [11]. The chromosomal rearrangement was investigated in more detail using $\mathrm{BAC}$ clones, RP11-91A14 and RP11-770J1 covering MLL and CTD-2238E23, CTD-2565C16 and CTD-2511C7 spanning FLNA. A fusion signal involving $M L L$ and FLNA was 


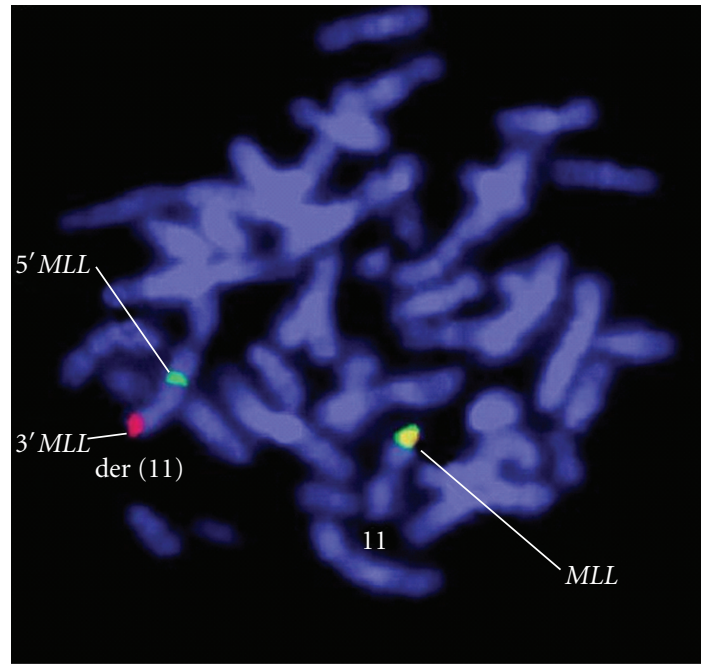

(a)

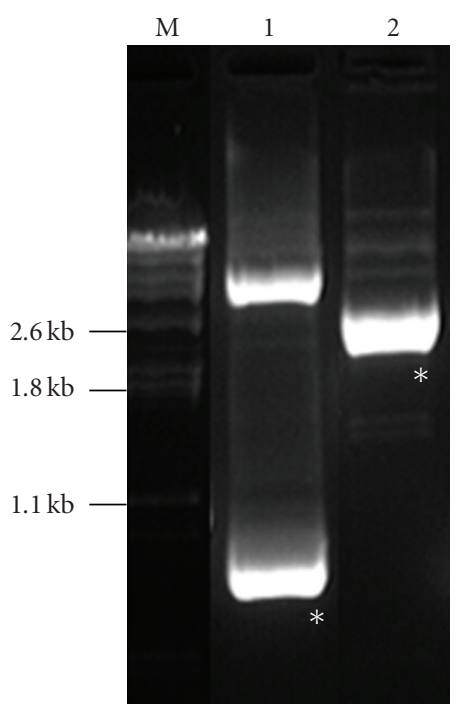

(b)

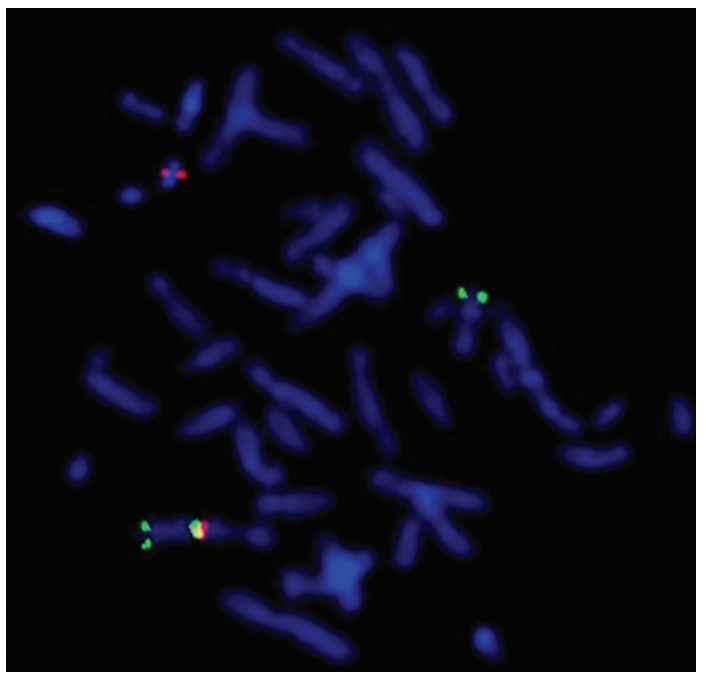

(c)

FIgURE 3: Identification of a new partner gene, FLNA, fused to MLL in acute myelomonoblastic leukemia. (a) FISH with dual-color MLL probe showing the insertion of chromosomal material within the disrupted signal of the MLL gene on the der(11). The yellow signal of the normal MLL is seen on the normal chromosome 11. (b) LDI-PCR of analyzed patient. The wild-type band in lane 2 does not appear. M: $\lambda$-Clal marker, 1: der(11), 2: der(reciprocal partner gene), ${ }^{*}$ : derivative band. (c) FISH with BAC clones CTD-2238E23 (FLNA) (labeled in Spectrum Orange) and RP11-91A14 (MLL) (labeled in FITC) showing two green signals, two red signals and one yellow signal.

observed (Figure 3(c)). RT-PCR confirmed that this $M L L-$ FLNA fusion gene was transcribed.

\section{Extent of Deletions}

Chromosomal deletion is commonly observed in hematological diseases. Deletions of some chromosome arms, such as $5 \mathrm{q}, 7 \mathrm{q}$ and $20 \mathrm{q}$, are recurrently identified in myelodysplastic syndromes, myeloproliferative neoplasms and acute myeloblastic leukemia.

However, the degree of elongation of the chromosomes does not allow the boundaries of the deletions to be precisely defined between patients, or even between different clones in a same patient. Fluorescent in situ hybridization with BAC clones can then be used to determine the size and boundaries of deletions. This is illustrated by the following two examples.

4.1. Delineation of $5 q$ Deletions in Several Clones of a Patient with Myelodysplastic Syndrome. This 74-year-old male patient was first seen because of a history of anemia. Microscopic examination of the bone marrow aspirate revealed morphologic abnormalities of the megakaryocytic lineage, especially monolobulated nuclei resembling those of the 5q-syndrome, associated with other features consistent with dysgranulopoiesis and dyserythropoiesis. 
TABLE 1: FISH results with BAC clones located on the long arm of chromosome 5. Delineation of deleted ( $\square$ ) and retained ( $\square$ ) regions of chromosome 5 in clones A, B, and C.

\begin{tabular}{|c|c|c|c|c|c|}
\hline Cytogenetic band & BAC clone & Position & $\begin{array}{c}\text { clone A } \\
\operatorname{del}(5)\end{array}$ & $\begin{array}{c}\text { clone B } \\
\operatorname{der}(5)\end{array}$ & $\begin{array}{c}\text { clone C } \\
\operatorname{der}(5)\end{array}$ \\
\hline $\mathrm{q} 11.2$ & RP11-300G6 & $51,53-51,71$ & $\boldsymbol{\square}$ & $\boldsymbol{\square}$ & $\square$ \\
\hline $\mathrm{q} 11.2$ & RP11-343F4 & $52,93-53,12$ & $\mathbf{\square}$ & $\mathbf{\square}$ & $\mathbf{\square}$ \\
\hline $\mathrm{q} 14.3$ & RP11-467D4 & $87,60-87,78$ & $\square$ & $\mathbf{\square}$ & $\square$ \\
\hline $\mathrm{q} 14.3$ & RP11-44N15 & $87,80-87,99$ & $\square$ & $\square$ & $\square$ \\
\hline $\mathrm{q} 22.3$ & RP11-68A11 & $114,44-114,61$ & $\square$ & $\square$ & $\square$ \\
\hline $\mathrm{q} 22.3$ & RP11-930P16 & $115,07-115,26$ & $\mathbf{\square}$ & $\mathbf{\square}$ & $\square$ \\
\hline $\mathrm{q} 31.2$ & RP11-103I17 & $135,37-135,54$ & $\square$ & $\mathbf{\square}$ & $\square$ \\
\hline $\mathrm{q} 31.2$ & RP11-27C15 & $136,78-136,96$ & $\square$ & $\square$ & $\square$ \\
\hline $\mathrm{q} 33.1$ & RP11-1152G8 & $151,04-151,17$ & $\mathbf{\square}$ & $\square$ & $\square$ \\
\hline $\mathrm{q} 33.1$ & RP11-602K10 & $151,16-151,33$ & $\square$ & $\square$ & $\square$ \\
\hline $\mathrm{q} 33.3$ & RP11-152N9 & $156,68-156,88$ & $\mathbf{\square}$ & $\square$ & $\square$ \\
\hline $\mathrm{q} 33.3$ & RP11-631N12 & $157,00-157,17$ & $\mathbf{\square}$ & $\boldsymbol{\square}$ & $\square$ \\
\hline
\end{tabular}

TABLE 2: Size and boundaries of commonly deleted regions in del(20q) and ider(20q) patients.

\begin{tabular}{lccccc}
\hline & $\operatorname{del}(20 \mathrm{q})$ MDS & $\operatorname{del}(20 \mathrm{q}) \mathrm{MPN}$ & $\operatorname{del}(20 \mathrm{q}) \mathrm{MDS} / \mathrm{MPN}$ & ider(20q) MDS & All patients \\
\hline Proximal breakpoint & RP11-1039F8 & RP11-467A7 & RP11-298O1 & RP11-60H7 & RP11-1039F8 \\
Distal breakpoint & RP11-293N18 & RP11-1013P13 & RP11-171L8 & RP11-124P7 & RP11-171L8 \\
Size $(\mathrm{Mb})$ & 10.4 & 7.4 & 7.9 & 17.9 & 6.6 \\
\hline
\end{tabular}

MDS: myelodysplastic syndrome; MPN: myeloproliferative neoplasm.

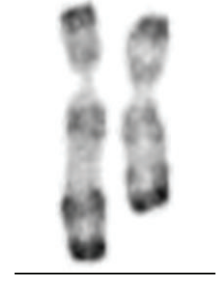

Clone A

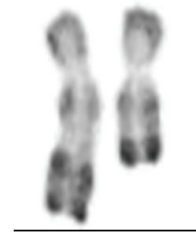

Clone B

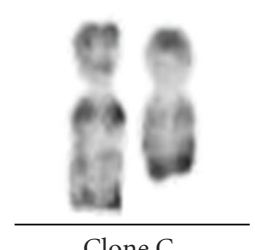

Clone C
FIGURE 4: RHG banding of chromosomes 5 in a patient with three different clones.

Chromosome banding analysis showed three clones (Figure 4): 46,XY,del(1)(p34),del(5)(q14q23) [2] (clone A)/ 46,XY, del(1)(p34), del(5)(q14q34) [10] (clone B)/46,sl2, $\operatorname{inv}(\underline{5})(\mathrm{q}$ ?11q?34) [7] (clone C). In order to precisely determine the breakpoints (proximal and distal), leading to the definition of the deleted region in this patient, metaphase FISH mapping was performed with an appropriate set of 20 BAC clones.

The complex nature of deleted chromosomes 5 in the three clones was revealed by sequential hybridization (Table 1). Clone A exhibited a deletion of some $27 \mathrm{Mb}$ between bands $5 q 14.3$ and $5 q 22.3$. The same deletion was observed in clones $\mathrm{B}$ and $\mathrm{C}$ but a more distal deletion of about $20 \mathrm{Mb}$ between bands $5 \mathrm{q} 31.2$ and $5 \mathrm{q} 33.3$ was also found in both clones.

4.2. Dissection of Chromosome 20 in Hematological Disorders. Deletion of the long arm of chromosome $20[\operatorname{del}(20 \mathrm{q})]$ is a recurrent abnormality observed in myelodysplastic syndromes and in Philadelphia-chromosome-negative myeloproliferative neoplasms [5]. Isochromosome of the long arm of chromosome 20 with loss of interstitial material [ider(20q)] is a variant of deletion of chromosome $20 \mathrm{q}$ and a rare abnormality in myelodysplastic syndrome [12].

A deletion of the long arm of chromosome 20 was detected by RHG banding in 38 patients, including 22 with myelodysplastic disorders (MDS), 12 with Philadelphiachromosome-negative myeloproliferative neoplasms (MPN) and 4 with MDS/MPN. An ider(20q) was identified in 7 patients with MDS. Sixty-six BAC clones distributed between bands 20q11.1 and 20q13.33 were used to determine not only both proximal and distal breakpoints of the $\operatorname{del}(20 \mathrm{q})$ and ider(20q) but also the size of the commonly deleted region (CDR) in each subpopulation of patients (Table 2).

The location of the proximal and distal breakpoints was highly variable among patients with $\operatorname{del}(20 q)$ or $\operatorname{ider}(20 q)$. Although no recurrent breakpoint was found, the distal 


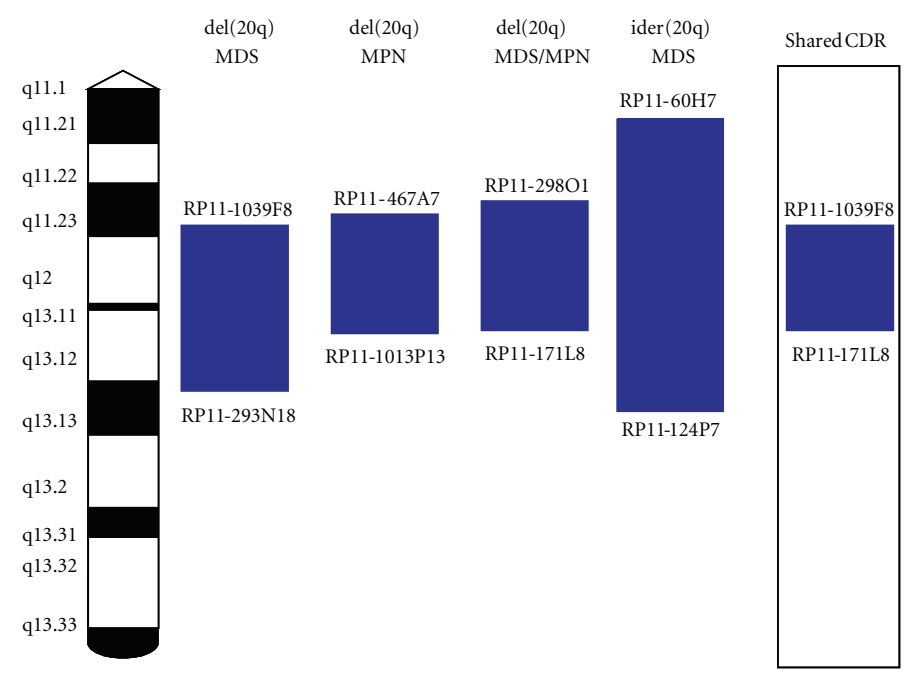

FIGURE 5: Ideogram of the long arm of chromosome 20. Delineation of commonly deleted regions (CDR). MDS: myelodysplastic syndrome; MPN: myeloproliferative neoplasm.

breakpoint occurred between RP11-112L6 and RP11-80K6 in a 2.6 megabases interval in 16 of the 38 patients with $\operatorname{del}(20 \mathrm{q})$. The proximal breakpoint was located in band 20q11.21 for all patients with $\operatorname{ider}(20 \mathrm{q})$, between RP11392M18 and RP11-60H7, in a 1 megabase interval. A recurrent breakpoint located between RP11-392M18 and RP11-380E19 was even observed in $57 \%$ of the patients with $\operatorname{ider}(20 q)[5,12]$.

Although the shared commonly deleted region encompassed $6.6 \mathrm{Mb}$, being located between bands q12 and q13.1, differences in size and location were observed between the three groups with $\operatorname{del}(20 \mathrm{q})$ whereas the size of CDR in patients with ider(20q) was much larger (17.9 megabases) (Figure 5) [5, 12].

\section{Conclusion}

The development of the Bacterial Artificial Chromosome system was driven in part by the Human Genome Project in order to construct genomic DNA libraries and physical maps for genomic sequencing [13]. BACs have now become essential tools in cancer research. One limitation to the system is that it can only accommodate inserts of up to $300 \mathrm{~kb}$. As a consequence, analyzing the extent of deletions with BAC clones requires a large amount of material. Array comparative genomic hybridization (array-CGH) using a BAC/PAC system can be an alternative. However, this technique has also limitations and it cannot be used to identify candidate genes at breakpoints of chromosomal rearrangements such as translocations, insertions and inversions.

\section{Acknowledgment}

This work was supported in part by the Ligue contre le Cancer-Comité du Finistère. E. De Braekeleer and N. DouetGuilbert equally contributed to this paper.

\section{References}

[1] A. P. Monaco and Z. Larin, "YACs, BACs, PACs and MACs: artificial chromosomes as research tools," Trends in Biotechnology, vol. 12, no. 7, pp. 280-286, 1994.

[2] K. D. Ball and J. T. Trevors, "Bacterial genomics: the use of DNA microarrays and bacterial artificial chromosomes," Journal of Microbiological Methods, vol. 49, no. 3, pp. 275-284, 2002.

[3] H. Shizuya and H. Kouros-Mehr, "The development and applications of the bacterial artificial chromosome cloning system," Keio Journal of Medicine, vol. 50, no. 1, pp. 26-30, 2001.

[4] ISCN, An International System for Human Cytogenetic Nomenclature, S. Karger, Basel, Switzerland, 2005.

[5] N. Douet-Guilbert, A. Basinko, F. Morel et al., "Chromosome 20 deletions in myelodysplastic syndromes and Philadelphiachromosome-negative myeloproliferative disorders: characterization by molecular cytogenetics of commonly deleted and retained regions," Annals of Hematology, vol. 87, no. 7, pp. 537-544, 2008.

[6] M. R. Wang, B. Perissel, and P. Malet, "Rehybridization on metaphases studied previously by FISH: an approach to analyze chromosome aberrations," Cancer Genetics and Cytogenetics, vol. 85, no. 1, pp. 58-60, 1995.

[7] A. Tempescul, G. Guillerm, N. Douet-Guilbert, F. Morel, M. J. Le Bris, and M. De Braekeleer, "Translocation $(10 ; 17)(\mathrm{p} 15 ; \mathrm{q} 21)$ is a recurrent anomaly in acute myeloblastic leukemia," Cancer Genetics and Cytogenetics, vol. 172, no. 1, pp. 74-76, 2007.

[8] E. De Braekeleer, N. Douet-Guilbert, M. J. Le Bris, C. Berthou, F. Morel, and M. De Braekeleer, "A new partner gene fused to $A B L 1$ in a $\mathrm{t}(1 ; 9)(\mathrm{q} 24 ; \mathrm{q} 34)$-associated $\mathrm{B}$-cell acute lymphoblastic leukemia," Leukemia, vol. 21, no. 10, pp. 22202221, 2007.

[9] C. Meyer, B. Schneider, M. Reichel et al., "Diagnostic tool for the identification of MLL rearrangements including unknown partner genes," Proceedings of the National Academy of Sciences of the United States of America, vol. 102, no. 2, pp. 449-454, 2005. 
[10] B. Arnaud, F. Morel, N. Douet-Guilbert, M. J. Le Bris, and M. De Braekeleer, "X chromosome insertion in the MLL gene in a case of childhood acute myeloblastic leukemia," Cancer Genetics and Cytogenetics, vol. 152, no. 2, pp. 149-152, 2004.

[11] E. De Braekeleer, N. Douet-Guilbert, F. Morel et al., "FLNA, a new partner gene fused to MLL in a patient with acute myelomonoblastic leukaemia," British journal of haematology, vol. 146, no. 6, pp. 693-695, 2009.

[12] N. Douet-Guilbert, J. L. Laï, A. Basinko et al., "Fluorescence in situ hybridization characterization of ider(20q) in myelodysplastic syndrome," British Journal of Haematology, vol. 143, no. 5, pp. 716-720, 2008.

[13] H. Shizuya, B. Birren, U. J. Kim et al., "Cloning and stable maintenance of 300-kilobase-pair fragments of human DNA in Escherichia coli using an F-factor-based vector," Proceedings of the National Academy of Sciences of the United States of America, vol. 89, no. 18, pp. 8794-8797, 1992. 

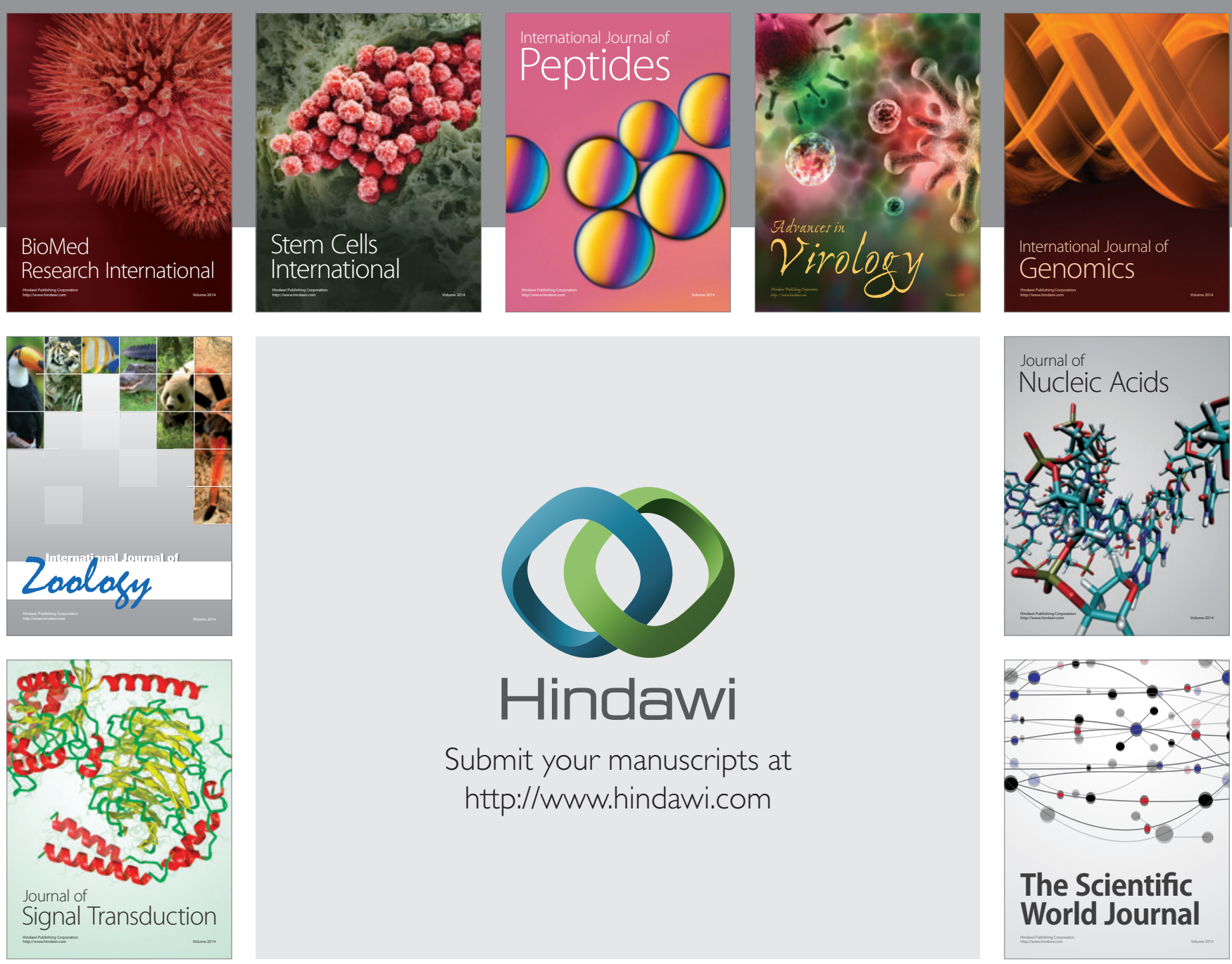

Submit your manuscripts at

http://www.hindawi.com
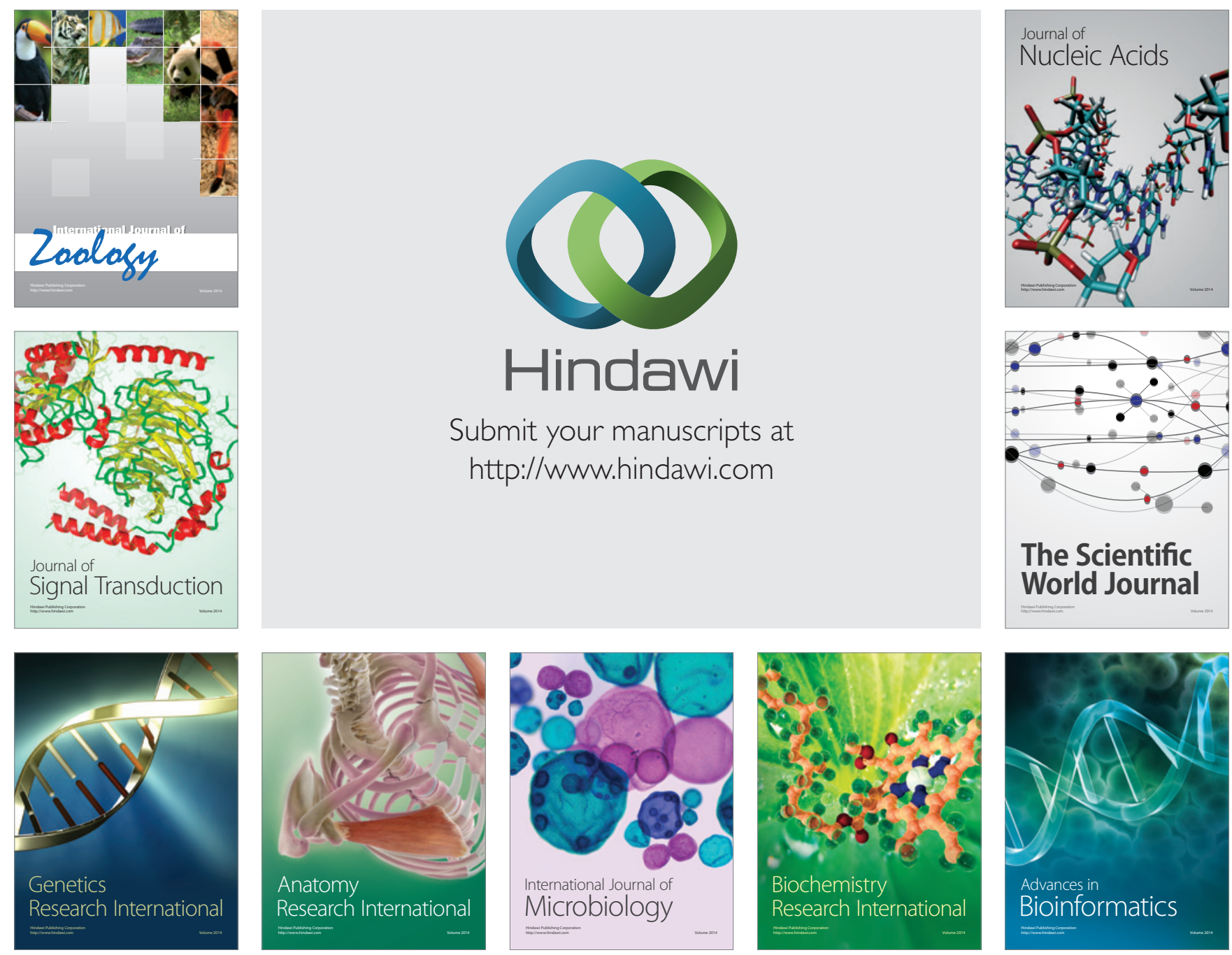

The Scientific World Journal
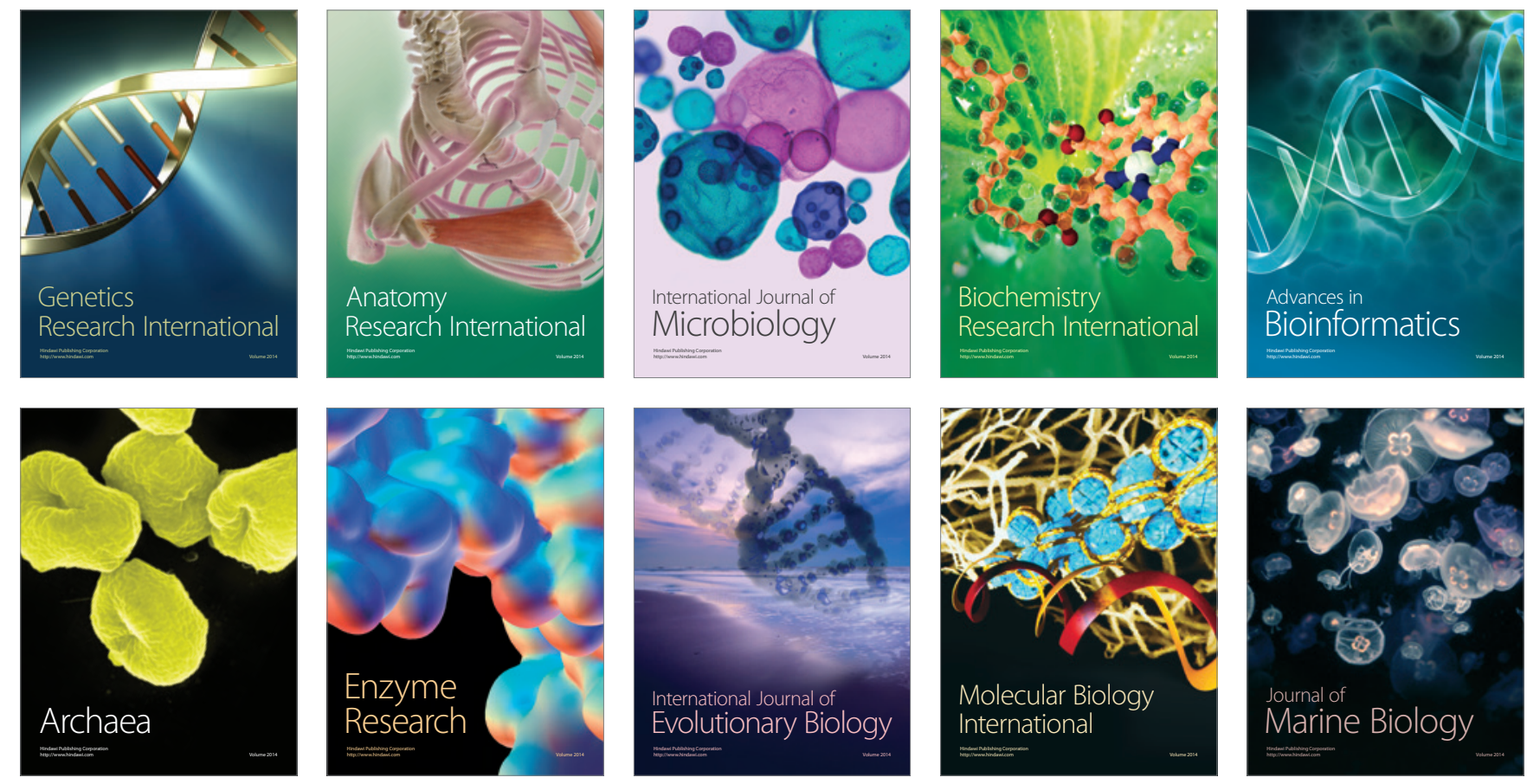